\title{
Comparative in-vivo Evaluation of Anti-Cancer Drugs Loaded Nanospheres
}

\author{
Prakash Katakam ${ }^{1}$, Phalguna Yadagiri ${ }^{2 *}$ \\ ${ }^{1}$ Professorand Prinicipal SSS Indira college of Pharmacy, Sahayog Educational Campus, Vishnupuri, Nanded, Maharashtra, INDIA. \\ ${ }^{2}$ Department of pharmaceutics Jyothismathi college of Pharmacy, Turkapally(V), Shameerpet(M), Medchal-Dist. Telangana-500078, \\ INDIA.
}

\begin{abstract}
Objectives: objective of present research was to formulate and evaluate nanospheres of selected anticancer drugs, viz., Capecitabine (CPN), Tamoxifen (TAM) and Doxorubicin (DXO). The adverse effects associated with anticancer drugs which include are bonemarrow depression, cardio toxicity, diarrhoea, nausea and vomiting, stomatitis and dermatitis. Materials and Methods: Drug loaded nanospheres of polycaprolactone-chitosan in various drug: polymer ratios, cross linked with Tripolyphosphate were prepared by double emulsion solvent evaporation and solvent diffusion methods. Male white New Zeeland Rabbits(weighing about $2500 \mathrm{gm}$ ) were selected as the animalmodel. The rabbits selected for the study had no medicationfor two weeks prior to the study. Results and Discussion: The parameters like AUC(0-24) of DXO nanospheres $2362.0 \mathrm{ng} \cdot \mathrm{h} / \mathrm{mL}$, whereas DXO pure drug was $1956.5 \mathrm{ng} . \mathrm{h} / \mathrm{mL}$. AUC (0-24) of TAM nanospheres 5646.00 $\mathrm{ng} . \mathrm{h} / \mathrm{mL}$. Whereas TAM unadulterated medication was $4786.30 \mathrm{ng} . \mathrm{h} / \mathrm{mL}$. AUC (0-24) of CPN nanospheres $4927.40 \mathrm{ng} . \mathrm{h} / \mathrm{mL}$. Whereas CPN pure drug was $4027.5 \mathrm{ng} . \mathrm{h} / \mathrm{mL}$. Conclusion: In vivo results showed a significant increase in the bioavailability of drugs from DX06, CPN6 and TAM6 nanospheres when compared to those of the standard drugs. This enhanced bioavailability could be helpful in reducing the dose of DXO, CPN and TAM and also reduce their toxicities. This enhanced bioavailability could be helpful in reducing the dose and also reduce the toxicities of the selected drugs.
\end{abstract}

Key words: Doxorubicin, Tamoxifen, Capecitabine, Nanospheres, in vivo studies.

\section{INTRODUCTION}

Tamoxifen (TAM) is a nonsteroidal specialist that ties to estrogen receptors (ER), propose a conformational change in the receptor. The outcome is a blockage or change in the indication of estrogen qualities. ${ }^{1}$ TAM is utilized to treat a breast tumor that has reach out to different parts of the body, to treat breast growth in specific patients after surgery and radiation treatment. Doxorubicin (DXO) has antimitotic and cytotoxic activity through a numeral of future components of activity. DXO shapes edifices with DNA by intercalation between base sets, and it restrains topoisomerase II movement by settling the DNA-topoisomerase II complex. DXO is an anthracycline sort of chemotherapy that is utilized alone or with different medications to treat a few distinct sorts of breast tumor. ${ }^{2}$ Capecitabine $(\mathrm{CPN})$ is a prodrug that is specifically tumor-initiated to its cytotoxic moiety ${ }^{3}$ fluorouracil, by thymidine phosphorylase. ${ }^{4} \mathrm{CPN}$ is utilized alone or with different medicines/drugs to take care of positive sorts of malignancy like colon, rectum. ${ }^{5}$ The adverse effects associated with anticancer drugs which include are bone-marrow depression, cardio toxicity, diarrhoea, nausea and vomiting, stomatitis and dermatitis. ${ }^{6}$ Therefore the objective of the present study was to evaluate the bioavailability studies of these drugs in order to eliminate its adverse effects.

Nanoparticles take an interest to a great degree basic obligation in tumor study. Because of a massively minimal size of nanoparticles they are basically and included
Submission Date: 17-04-2017; Revision Date: 18-06-2017; Accepted Date: 13-07-2017

DOI: 10.5530/ijper.51.4s.88 Correspondence: Dr. Phalguna Yadagiri, Department of pharmaceutics Jyothismathi college of Pharmacy, Turkapally (V), Shameerpet (M), Medchal, Telangana-500078, INDIA.

Phone no. 08985153205

E-mail: yphalgun@gmail.com

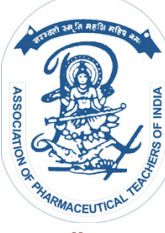

www.ijper.org 
deliberately taken up by the human body. ${ }^{7}$ Nanoparticles are steady strong colloidal particles comprise of biodegradable polymer or lipids and size range 10-1000 $\mathrm{nm}$. Formulation, characterization and in vitro evaluation of DXO, ${ }^{8}$ TAM, ${ }^{9}$ and $\mathrm{CPN},{ }^{10}$ loaded nanospheres have already been discussed in our previous articles. Moreover this In vivo evaluation has not been reported in the literature. Therefore in this article we evaluate the bioavaliability studies for different anticancer drugs and compared with pure drugs.

\section{MATERIALS AND METHODS}

Doxorubicin was a gift sample from Sun Pharmaceutical Ltd., Mumbai, India. Tamoxifen was a gift sample from the Cipla Limited, Mumbai, India. Capecitabine was a gift sample from the Dr. Reddy lab's., Hyderabad, India. Polycaprolactone (Mw 14, 000), chitosan (Mw 60, 000120, 000), sodium tripolyphosphate (Mw 367.86) and polyvinyl alcohol (Mw 7, 200) were purchased from Sigma Aldrich Pvt. Ltd., Bangalore, India. Dialysis membrane (average diameter $21.5 \mathrm{~mm}$ and capacity 3.63 $\mathrm{ml} / \mathrm{cm}$ ) was from Himedia Pvt. Ltd., Mumbai, India. All other reagents used were of analytical grade.

\section{Preparation of nanospheres}

The DXO loaded nanospheres were formulated using two methods. Polycaprolactone (PCL), chitosan, sodium tripolyphosphate (TPP), polyvinyl alcohol (PVA) combinations at various concentrations. Formulations DXO1-DXO3, TAM1-TAM3, CPN1-CPN3 were prepared by double-emulsion solvent evaporation method. ${ }^{11}$ using polycaprolactone and chitosan each at concentrations of $0.5,1.5$ and $2.5 \% \mathrm{w} / \mathrm{w}$ respectively. Similarly formulations DXO4-DXO6, TAM4-TAM6, CPN4-CPN6 were prepared by emulsion solvent diffusion method. ${ }^{12,13}$ using the same formula. In all, the six formulations, polyvinyl alcohol $(4 \% \mathrm{w} / \mathrm{w})$ and tripolyphosphate $(1 \% \mathrm{w} / \mathrm{w})$ were used as external aqueous phase (EAP) and cross-linking agent respectively.

\section{In vivo bioavailability studies of nanospheres}

All the animal investigations were performed as per the requisite protocol approved by the Animal Ethics Committee, Albino Research and Training Institute, Hyderabad, India. Approval letter No: ARTI/CPCSEA/2014/05. Male white New Zeeland Rabbits (weighing about $2500 \mathrm{gm}$ ) were selected as the animal model. The rabbits selected for the study had no medication for two weeks prior to the study. Animals were divided into seven groups each containing 3 rabbits. Group-I (control group), Group-II (CPN pure drug), Group - III (DXO pure drug), Group - IV (TAM pure drug), Group - V (CPN6 -nanospheres), Group - VI (DXO6-nanospheres) and Group - VII (TAM6- nanospheres). The rabbits were placed on their side on the surgery table and $0.5 \mathrm{~mL}$ of blood sample was collected from a retro - orbital vein at the time interval of 0,1 , $4,8,12,16,20$, and $24 \mathrm{~h}$ for all the seven groups. The blood samples were allowed to coagulate and whole blood samples were centrifuged and plasma was separated and stored at $-20^{\circ} \mathrm{C}$ until analyzed.

\section{Analysis of Plasma samples by LC/MS method}

The chromatographic system consisted of an Agilent HPLC with a UV-visible detector (UVD170U). The separation was achieved by using Orochem PD, RP18, $(4.6 \mathrm{~mm}$ i.d. $\times 15 \mathrm{~mm}$ ) analytical column (Waters, Milford, MA, USA) which is operated at $40^{\circ} \mathrm{C}$. The mobile phase was an isocratic elution with a flow rate of $1200 \mu \mathrm{L} / \mathrm{min}$ and consisted mixture of $5 \mathrm{MM}$ Ammonium Format: Methanol (20:80, v/v. ${ }^{14}$ Under these conditions, RTs were typically $1.10 \mathrm{~min}$ for Capecitabine approximately. The Column effluent was introduced into the mass. The temperature of the auto sampler was kept $4^{\circ} \mathrm{C}$ and the run time was $2.0 \mathrm{~min}$.

The chromatographic system consisted of an Agilent HPLC with a UV-visible detector (UVD170U). The separation was achieved by using YMC Triat C18 column $(5 \mu, 100 \times 4.6 \mathrm{~mm}$ i.d.) analytical column (Waters, Milford, MA, USA) which is operated at $40^{\circ} \mathrm{C}$. The mobile phase was an isocratic elution with a flow rate of $600 \mu \mathrm{L} / \mathrm{min}$ and consisted mixture of $10 \mathrm{MM}$ Ammonium Acetate/Acetonitrile (40/60, v/v). ${ }^{15}$ Under these conditions, RTs were typically $1.10 \mathrm{~min}$ for Doxorubicin approximately. The Column effluent was introduced into the mass. The temperature of the auto sampler was kept $4^{\circ} \mathrm{C}$ and the run time was $2.0 \mathrm{~min}$.

The chromatographic system consisted of an Agilent HPLC with a UV-visible detector (UVD170U). The separation was achieved by using Symmetry Shield, C18, $(4.6 \mathrm{~mm}$ i.d. $\times 50 \mathrm{~mm}$ ) analytical column (Waters, Milford, MA, USA) which is operated at $40^{\circ} \mathrm{C}$. The mobile phase was an isocratic elution with a flow rate of $600 \mu \mathrm{L} / \mathrm{min}$ and consisted of $2 \mathrm{~mL}$ of Ethyl Acetate. ${ }^{16}$ Under these conditions, RTs were typically $1.10 \mathrm{~min}$ for Tamoxifen approximately. The Column effluent was introduced into the mass. The temperature of the auto sampler was kept $4^{\circ} \mathrm{C}$ and the run time was $2.0 \mathrm{~min}$.

\section{Mass spectrometry conditions for CPN, DXO, and TAM}

An API-4000 triple-quadrupole mass spectrometer (Applied Bios stems/MDS SCIEX, Foster City, CA/ Concord, Ontario, Canada) was equipped with an electro 
spray source (ESI), operating in the positive ion mode. Data were collected and processed using Scitex Analyst 1.4.2 Data collection and integration software on a DELL compatible computer using multiple reaction monitoring (MRM). Data were acquired on a Dell Precision 370 workstation and were processed using the Analyst 1.4.2 software package (MDS Scitex). Calibration curve Range: $5 \mathrm{ng} / \mathrm{mL}$ to $5000 \mathrm{ng} / \mathrm{Ml}$.

\section{Statistical analysis}

The measurable investigation of exploratory information used the student's t-test, and the outcomes are introduced as mean \pm sd. Statistical significance was accepted at a level of $p<0.05 .{ }^{17}$

\section{RESULTS AND DISCUSSION}

DXO1-DXO3, TAM1-TAM3, CPN1-CPN3 were successfully prepared by double emulsion solvent evaporation and DXO4-DXO6, TAM4-TAM6,CPN4CPN6 prepared by solvent diffusion method. Nanospheres were characterized in terms of particle size, zetepotential, polydispersity index, refractive index, SEM and in vitro release profile.

\section{Drug entrapment, PSA, ZP, SEM, PDI, RI and in vitro release of DXO}

Drug entrapment for DXO6 was found to be $93.62 \pm 0.17 \%$, particle size of the nanospheres was found in the range of $700 \pm 105$ to $770 \pm 115 \mathrm{~nm}$, Zeta potential was showed negative with $34.05 \pm 1.5 \mathrm{mV}$, Polydispersity index (0.316), Refractive index (1.33), In vitro drug release for DXO6 was $94.16 \pm 0.85 \%$ for a period of $24 \mathrm{~h}$.

\section{Drug entrapment, PSA, ZP, SEM, PDI, RI and in vitro release of TAM}

The drug entrapment for TAM6 was showed $90.56 \pm 0.45$, Particle size of nanospheres was found to be $620 \pm 50$ to $770 \pm 100 \mathrm{~nm}$, zeta potential was found to be $-72.59 \mathrm{mV}$, Polydispersity index(-5.83), Refractive index(1.33), The formulation TAM 6 showed $92.57 \pm 0.32 \%$ release of the drug for a period of $24 \mathrm{~h}$.

Drug entrapment, PSA, ZP, SEM, PDI, RI and in vitro release of $\mathrm{CPN}$

Drug entrapment for CPN6 was found to be $96.53 \pm 0.86$, maximum diameter of the particles is found to be $616 \pm 110$ to $713 \pm 115 \mathrm{~nm}$, zeta potential was found to be $-17.30 \mathrm{mV}$, Poly dispersity index(0.316), Refractive index(1.33), SEM photographs showed nanospheres of discrete nature, and distinct particle size and shape with a smooth surface, in vitro release profile showed maximum in CPN6 drug release of $94.28 \pm 0.20 \%$ for a period of 24 hrs.

\section{Kinetic studies}

The drug release profiles are fitted to release kinetics the slope for Kosmeyer-peppas was in the range of 0.45 to 1 indicating both diffusion and erosion of both biodegradable polymers. The release mechanisms for all the formulations followed by non-fickian diffusion mechanism.

\section{Bioavailability studies}

Based on the best release profiles of DXO6, TAM6 and CPN6 formulations were selected for In vivo studies. Bioavailability studies of optimized formulations were evaluated to prove their therapeutic efficacy. Bioavailability of developed nanospheres were also compared with pure drugs. The results of these studies are given in Table 1-3 and Figure 1-3 Nanospheres of DXO experienced in beginning an appearance with in $1^{\text {st }} \mathrm{h}$. nanospheres demonstrated higher blood concentration when contrasted with pure drug through the study. $\mathrm{T}_{\max }$ of DXO nanospheres and standard drug was found to be $12 \mathrm{~h}$ and $8 \mathrm{~h}$. Yet, $\mathrm{C}_{\max }$ and $A \mathrm{AUC}_{(0-2)}$ were higher for DXO nanospheres. The $\mathrm{C}_{\max }$ of nanospheres was found to be $156.30 \mathrm{ng} / \mathrm{mL}$, whereas for pure DXO it was $126.80 \mathrm{ng} / \mathrm{mL}$. The other parameters like $\mathrm{AUC}_{(0-24)}$ of DXO nanospheres $2362.0 \mathrm{ng} \cdot \mathrm{h} / \mathrm{mL}$, whereas DXO pure drug was $1956.5 \mathrm{ng} . \mathrm{h} / \mathrm{mL}$.

Nanospheres of TAM experienced in introductory appearance with in $1^{\text {st }} \mathrm{h}$. The nanospheres demonstrated higher blood focus when contrasted with pure drug through the study. $\mathrm{T}_{\max }$ of TAM nanospheres and standard medication was found to be $4 \mathrm{~h}$. Be that as it may, $\mathrm{C}_{\max }$ and $\mathrm{AUC}_{(0-24)}$ was higher for TAM nanospheres. $\mathrm{C}_{\max }$ of nanospheres was discovered to be $459.20 \mathrm{ng} / \mathrm{mL}$, whereas pure drug discovered to be $442.20 \mathrm{ng} / \mathrm{mL}$. The other parameter like AUC ${ }_{(0-24)}$ of TAM nanospheres 5646.00 ng.h/mL. Whereas TAM unadulterated medication was $4786.30 \mathrm{ng} . \mathrm{h} / \mathrm{mL}$.

Nanospheres of CPN experienced in beginning an appearance with in $1^{\text {st }} \mathrm{h}$. Nanospheres demonstrated higher blood focus when contrasted with pure drug through the study. $\mathrm{T}_{\max }$ of CPN nanospheres and standard medication was found to be $4 \mathrm{~h}$. Yet, $\mathrm{C}_{\max }$ and AUC (0-24) were higher for CPN nanospheres. $\mathrm{C}_{\max }$ of nanospheres was discovered to be $563.20 \mathrm{ng} / \mathrm{mL}$. Whereas pure drug discovered to be $456.20 \mathrm{ng} / \mathrm{mL}$. The other parameter like AUC (0-24) of CPN nanospheres $4927.40 \mathrm{ng} . \mathrm{h} / \mathrm{mL}$. Whereas $\mathrm{CPN}$ pure drug was 4027.5ng.h/mL. 


\section{Table 1: In vivo studies of standard DXO and optimized DXO6 Nanospheres.}

\begin{tabular}{|c|c|c|}
\hline $\begin{array}{c}\text { Time in } \\
\mathbf{h}\end{array}$ & $\begin{array}{c}\text { Concentration } \\
(\mathbf{n g} / \mathbf{m L}) \text { for standard } \\
\mathbf{D X O}\end{array}$ & $\begin{array}{c}\text { Concentration } \\
\mathbf{( n g / m L}) \text { for optimized } \\
\mathbf{D X O 6} \text { nanospheres }\end{array}$ \\
\hline 1 & $23.4 \pm 1.28$ & $42.3 \pm 1.11$ \\
\hline 4 & $86.2 \pm 0.78$ & $96.3 \pm 1.21$ \\
\hline 8 & $126.8 \pm 0.71$ & $145.3 \pm 1.17$ \\
\hline 12 & $106.2 \pm 1.15$ & $156.3 \pm 0.95$ \\
\hline 16 & $89.2 \pm 1.83$ & $99.2 \pm 1.02$ \\
\hline 20 & $65.2 \pm 1.34$ & $66.2 \pm 0.88$ \\
\hline 24 & $29.20 \pm 0.45$ & $36.2 \pm 1.05$ \\
$\mathrm{AUC}_{(0-24)}(\mathrm{ng} . \mathrm{h} / \mathrm{L})$ & $1956.50 \pm 23.86$ & $2362 \pm 21.31$ \\
$\mathrm{C}_{\max }(\mathrm{ng} / \mathrm{L})$ & $126.80 \pm 0.711$ & $156.3 \pm 0.95$ \\
$\mathrm{~T}_{\max }$ & 8 & 8 \\
\hline
\end{tabular}

Table 2: In vivo studies of standard TAM and optimized TAM6 nanospheres.

\begin{tabular}{|c|c|c|}
\hline $\begin{array}{c}\text { Time in } \\
\mathbf{h}\end{array}$ & $\begin{array}{c}\text { Concentration } \\
(\mathbf{n g} / \mathbf{m L}) \text { for standard } \\
\text { TAM }\end{array}$ & $\begin{array}{c}\text { Concentration } \\
\text { (ng/mL) for optimized } \\
\text { TAM6 nanospheres }\end{array}$ \\
\hline 1 & $66.2 \pm 1.41$ & $86.2 \pm 1.25$ \\
\hline 4 & $442.2 \pm 1.47$ & $459.2 \pm 1.48$ \\
\hline 8 & $326.0 \pm 1.07$ & $339.2 \pm 1.32$ \\
\hline 12 & $223.3 \pm 1.34$ & $269.8 \pm 0.95$ \\
\hline 16 & $106.4 \pm 1.16$ & $208.2 \pm 1.22$ \\
\hline 20 & $89.7 \pm 1.07$ & $106.3 \pm 1.34$ \\
\hline 24 & $62.1 \pm 1.38$ & $86.2 \pm 1.09$ \\
$\mathrm{AUC}_{(0-24)}(\mathrm{ng} . \mathrm{h} / \mathrm{L})$ & $4785.09 \pm 25.4$ & $5646.02 \pm 28.86$ \\
$\mathrm{C}_{\max }^{(\mathrm{ng} / \mathrm{L})}$ & $442.20 \pm 1.47$ & $459.2 \pm 1.4$ \\
$T_{\max }$ & 4 & 4 \\
\hline
\end{tabular}

\section{Table 3: In vivo studies of standardCPN and optimized CPN6 nanospheres.}

\begin{tabular}{|c|c|c|}
\hline $\begin{array}{c}\text { Time in } \\
\mathbf{h}\end{array}$ & $\begin{array}{c}\text { Concentration } \\
(\mathbf{n g} / \mathbf{m L}) \text { for standard } \\
\mathbf{C P N}\end{array}$ & $\begin{array}{c}\text { Concentration } \\
\text { (ng/mL) for optimized } \\
\text { CPN6 nanospheres }\end{array}$ \\
\hline 1 & $38.60 \pm 0.95$ & $45.9 \pm 1.08$ \\
\hline 4 & $456.20 \pm 1.08$ & $563.2 \pm 1.32$ \\
\hline 8 & $312.0 \pm 1.03$ & $382.6 \pm 1.11$ \\
\hline 12 & $156.0 \pm 1.11$ & $186.2 \pm 1.47$ \\
\hline 16 & $78.2 \pm 1.13$ & $89.2 \pm 1.39$ \\
\hline 20 & $36.1 \pm 1.17$ & $46.3 \pm 1.46$ \\
\hline 24 & $12.2 \pm 1.21$ & $23.6 \pm 1.13$ \\
$\mathrm{AUC}_{(0-24)}(\mathrm{ng} . \mathrm{h} / \mathrm{L})$ & $4027.50 \pm 19.59$ & $4927 \pm 29.84$ \\
$\mathrm{C}_{\max }(\mathrm{ng} / \mathrm{L})$ & $456.20 \pm 1.08$ & $562.7 \pm 1.32$ \\
\hline
\end{tabular}

\section{Statistical analysis}

It was observable that the distinction in bioavailability was $\mathrm{P}=0.027$ for $\mathrm{CPN}, \mathrm{P}=0.018$ for $\mathrm{DXO}$ and $\mathrm{P}=0.016$ for TAM beteen the standard and tested nanospheres. This shows that the arranged nanospheres demonstrated fundamentally better bioavailability with that of the standard. 


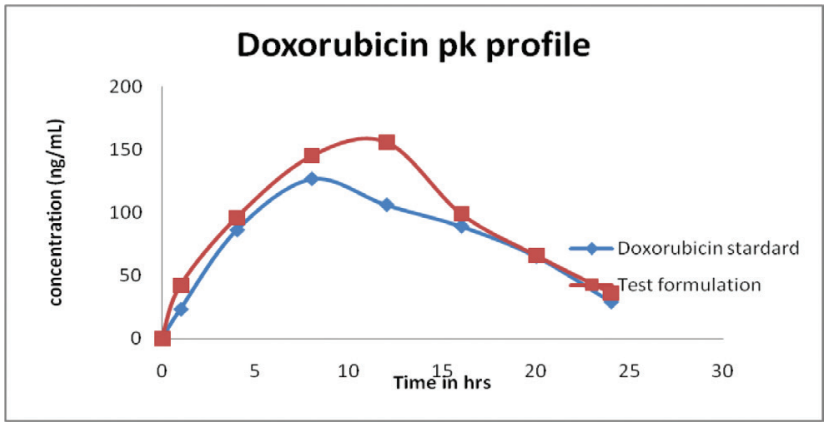

Figure 1: DXO comparative Pharmacokinetic (s) profile.

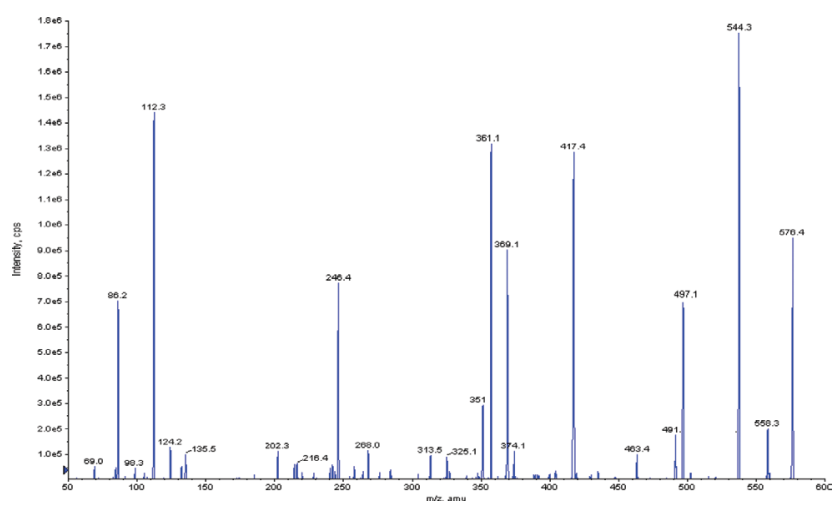

Figure 2: Mass spectra for DXO.

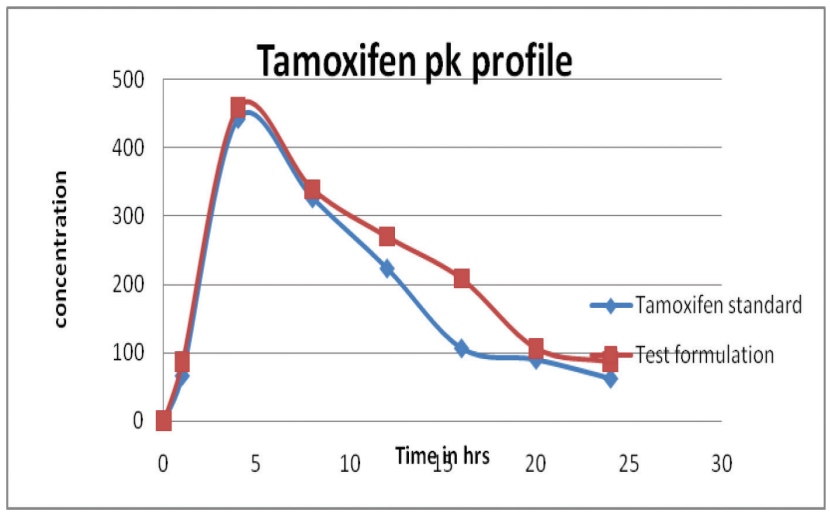

Figure 3: TAM comparative Pharmacokinetic (s) profile.

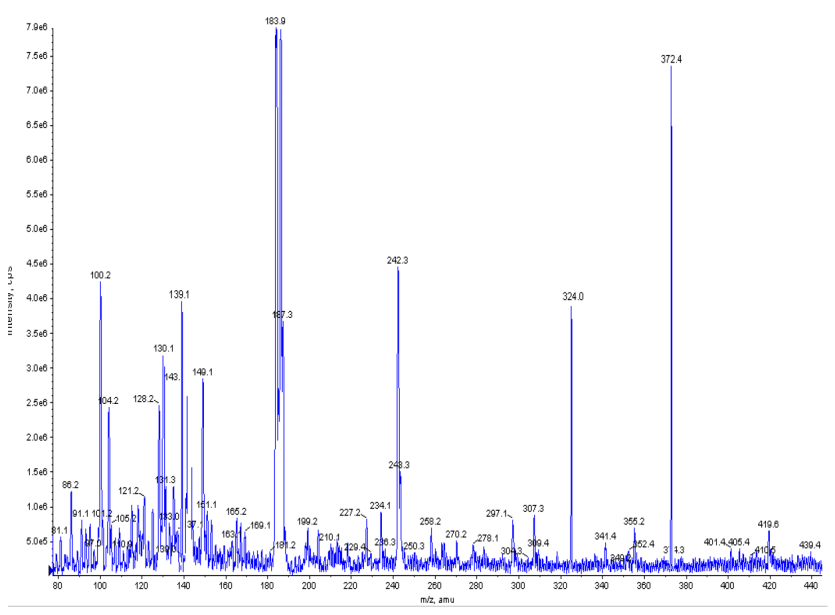

Figure 4: Mass spectra for TAM.

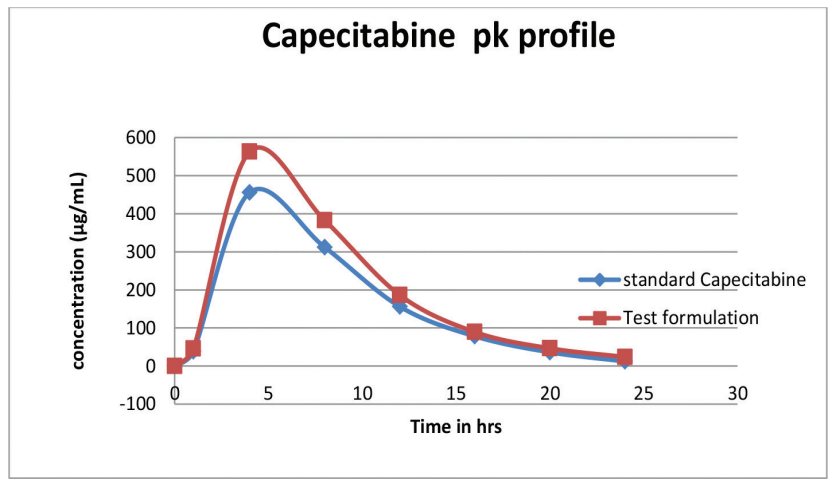

Figure 5: CPN comparative Pharmacokinetic (s) profile.

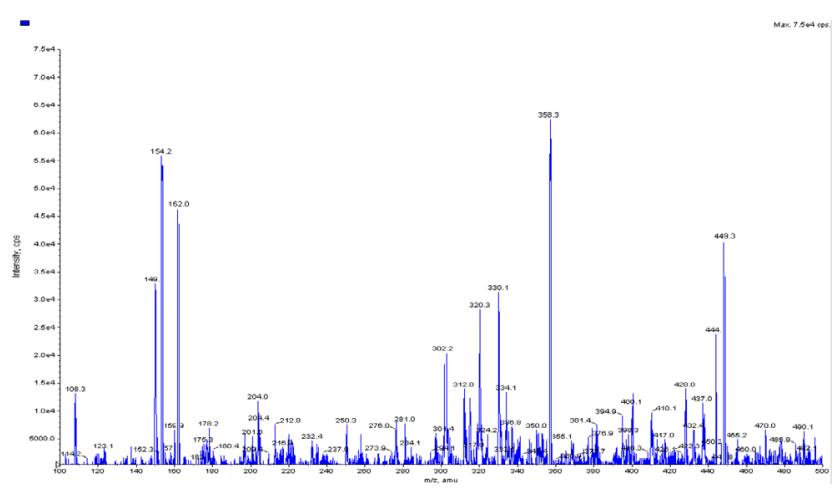

Figure 6: Mass spectra for CPN.

\section{CONCLUSION}

In vivo results showed a significant increase in the bioavailability of drugs from DXO6, CPN6 and TAM6 nanospheres when compared to those of the standard drugs. This enhanced bioavailability could be helpful in reducing the dose of $\mathrm{DXO}, \mathrm{CPN}$ and TAM and also reduce their toxicities. The present investigation shows a promising future on the nanospheres formulations of the selected anticancer drugs, viz., DXO $(\mathrm{p}=0.018)$, CPN ( $p=0.027)$ and TAM $(p=0.016)$. This research throws light on the novel drug delivery systems for the selected drugs. From the results it can be concluded that the developed nanospheres have great potential for parenteral application of DXO, TAM and CPN.

\section{ACKNOWLEDGEMENT}

Authors sincerely thank to the management, Jyothishmathi College of Pharmacy, Turkapally, Medchal, Telangana.

\section{CONFLICT OF INTEREST}

There are no conflicts of interest. 


\section{ABBREVIATION USED}

TAM: Tamoxifen DXO: Doxorubicin; CPN: Capecitabine; ER: Estrogen receptors; EAP: External aqueous phase; ESI: Electro spray source.

\section{REFERENCES}

1. Steiner $\mathrm{AZ}$, Terplan M, Paulson RJ. Comparison of tamoxifen and clomiphene citrate for ovulation induction: a meta-analysis. Hum Reprod. 2005;20(6):1511-5.

2. Valery A, Evgueni K. From cell screen to clinical trials. Colloids and Surfaces B:Biointerface. 1999;16:113-34.

3. Eliason JF, Megyeri A. Potential for predicting toxicity and response of fluoropyrimidines in patients. Curr Drug Targets. 2004;5(4):383-8.

4. Carlini LE, Meropol NJ, Bever J. UGT1A7 and UGT1A9 polymorphisms predict response and toxicity in colorectal cancer patients treated with capecitabine/irinotecan. Clin Cancer Res. 2005;11(3):1226-36.

5. Silvestris N, Maiello E. Update on capecitabine alone and in combination regimens incancer patients. Cancer Treatment Reviews. 2010;36(S3):S46-S55.

6. Hoff M, Rafat A, Gerald B. Comparison of oral capecitabine versus intravenous fluorouracil plus leucovorin as first-line treatment in 605 patients with metastatic colorectal cancer: Results of a randomized phase III study. Journal of Clinical Oncology. 2001;19(8):2282-92.

7. Kayserl $O$. The impact of nanobiotechnology on the development of new drug delivery systems. Curr Pharm Biotech. 2005;6:3-5.

8. Phalguna Y, Prakash K. Doxorubicin loaded polycaprolactone-chitosan Nanospheres: Formulation, characterization and in vitro evaluation. Indian Drugs. 2014;51(11):17-23.

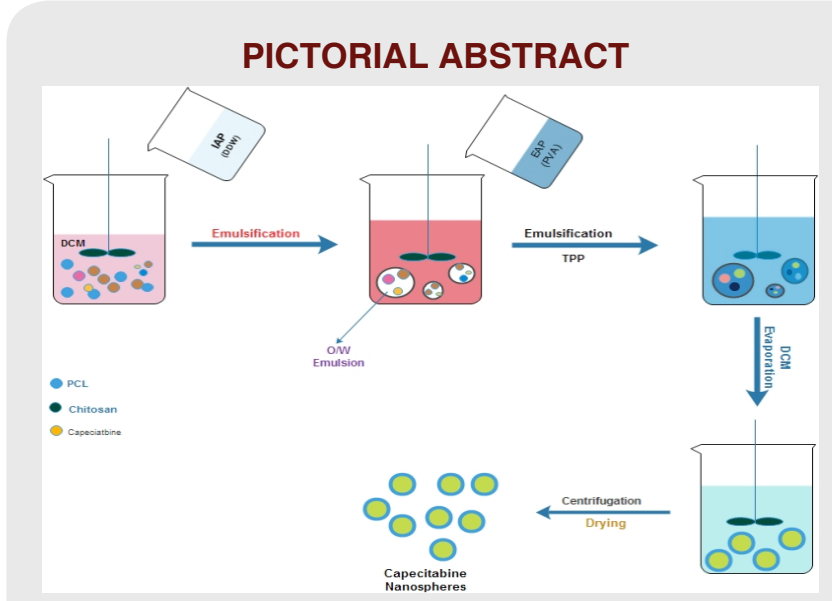

9. Phalguna $\mathrm{Y}$, Prakash K. Formulation, characterization and in vitro evaluation of tamoxifen loaded PCL-chitosan nanospheres. Int J Pharmaceutics (Recent science). 2014;30(1):1174-9.

10. Phalguna $\mathrm{Y}$, Prakash K. Formulation, characterization and in vitro evaluation of capecitabine loaded PCL-chitosan nanospheres. BPJ. 2014;17(1):18-24.

11. Lee M, Cho Y. Size control of self-assembled nanoparticles by an emulsion/ solvent evaporation method. Colloid Polym Sci. 2006;284(5):506-12.

12. Leroux JC, Allemann E. New approach for the preparation of nanoparticles by an emulsification diffusion method. Eur j pharm Biopharm. 1995;41(1):14-18.

13. Quintanar GD, Ganem QA. Influence of the stabilizer coating layer on the purification and freeze drying of poly (DL-lactic acid) nanoparticles prepared by emulsification-diffusion technique. J Microencapsulation. 1998;15(1):107-19.

14. Grem L, Xu Y. Liquid chromatography-Mass spectrometry method for the analysis of the anti-cancer agent Capecitabine and its nucleoside metabolites in human plasma. Journal of Chromatography B. 2003;783(1):273-85.

15. Straubinger M, Robert D. Quantification of Doxorubicin and metabolites in rat plasma and small volume tissue samples by liquid chromatography/ electrospray tendom mass spectroscopy. Journal of Chromatography B. 2004;808(2):141-52.

16. Lien EA, Gjerde J. Identification and quantification of Tamoxifen and four metabolites in serum by liquid chromatography-tandem mass spectrometry. Journal of Chromatography A. 2005;1082:6-14.

17. Lin M, Cunxian S. A Novel Docetaxel- loaded PCL/pluronic F68 nanoparticle overming multidrug resistance for breast cancer treatment. Nanoscale Res Lett. 2009;4:1530-9.

\section{SUMMARY}

An attempt was made to formulate and evaluate nanospheres of selected anticancer drugs, viz., Capecitabine (CPN), Tamoxifen (TAM) and Doxorubicin (DXO).DX01-DXO3, TAM1-TAM3, CPN1-CPN3 were prepared by double emulsion solvent evaporation and DXO4-DX06, TAM4TAM6, CPN4- CPN6 prepared by solvent diffusion method. All the evaluation parameters were within the standard limits. The bioavailability of developed nanospheres were compared with standard and found to be much effective with better bioavailability.

\section{About Authors}

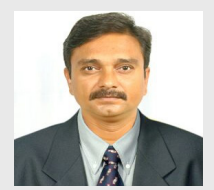

Dr.Prakash Katakam: Principal and professor, SSJ Indira college of pharmacy, Nanded, Maharastra, India. Professional Experience of over 20 years of teaching, research and administrative experience in pharmaceutical education. Five years of International Exposure worked in Libyan Govt. University and Visiting Professor of Belgrade University, Serbia.

Contributed 117 publications in national and international journals, Published 06 Indian patents. Presented research works in 15 conferences. Guided 08 PhD students and guiding 03 students.

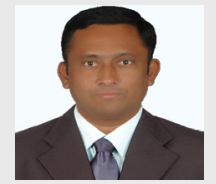

Dr.Y.Phalguna: HOD in Dept.of Pharmaceutics, Jyothismathi college of pharmacy, Turkapally. He has 13 years of experience in teaching and research. He published various papers in national and international journals.

Cite this article: Katakam P, Yadagiri P. Comparative in-vivo Evaluation of Anti-Cancer Drugs Loaded Nanospheres. Indian J of Pharmaceutical Education and Research. 2017;51(4S):S601-S6. 